\title{
Cell adhesion molecules in the pathogenesis of and host defence against microbial infection
}

\author{
J R Kerr
}

\begin{abstract}
Eukaryotic cell adhesion molecules (CAMs) are used by various cells and extracellular molecules in host defence against infection. They are involved in many processes including recognition by circulating phagocytes of a site of inflammation, transmigration through the endothelial barrier, diapedesis through basement membrane and extracellular matrix, and release of effector mechanisms at the infected site. CAMs involved in leucocyte-endothelial cell interaction include the selectins, integrins, and members of the immunoglobulin superfamily. However, CAMs are also used by various microorganisms (protozoa, fungi, bacteria, and viruses) during their pathogenesis. For example, bacteria that utilise CAMs include Mycobacterium tuberculosis, Listeria monocytogenes, Yersinia spp, enteropathogenic Escherichia coli, Shigella spp, Neisseria spp, Bordetella spp, and Borrelia burgdorferi. In addition, CAMs are involved in the pathogenetic effects of the RTX toxins of Pasteurella haemolytica, Actinobacillus actinomycetemcomitans, and the superantigen exotoxins of Staphylococcus aureus and Streptococcus pyogenes. A recurrent and topical theme of potential importance within the bacterial group is the intimate relation between CAMs, bacterial protein receptors, and type III secretion systems. For example, the IpaBCD protein complex is secreted by the type III system of Shigella flexneri and interacts with $\alpha_{5} \beta_{1}$ integrin on the eukaryotic cell surface, followed by Rho mediated internalisation; this illustrates the relevance of cellular microbiology. CAMs might prove to be novel therapeutic targets. Comparative genomics has provided the knowledge of shared virulence determinants among diverse bacterial genera, and will continue to deepen our understanding of microbial pathogenesis, particularly in the context of the interaction of prokaryotic and eukaryotic molecules.

(F Clin Pathol: Mol Pathol 1999;52:220-230)
\end{abstract}

Medical Microbiology,

Manchester Royal

Infirmary, Oxford

Road, Manchester

M13 9WL, UK

J R Kerr

Correspondence to: Dr Kerr.

Accepted for publication 20 April 1999

Keywords: cell adhesion molecules; microbial infection; host defence

The environment of any cell is a complex mixture of soluble molecules in the extracellular matrix (ECM), other cells, and insoluble molecules that form tissue matrices. Cell adhesion molecules (CAMs) are the means by which a cell communicates with other cells and the ECM. Thus, the cell samples its environment by means of complex arrays of CAMs present on the cell surface and integrated into the cell membrane. Although named "cell adhesion molecules" because they mediate cellular attachment to other cells and the ECM, this "stickiness" is not always the prime function of a particular molecule. For example, cellular attachment is the means by which a cell maintains itself in a certain relative location, to allow the cell to sample its environment and respond to molecules that are part of neighbouring cells and insoluble matrices.

All CAMs are transmembrane glycoproteins and have extracellular, transmembrane, and intracellular domains; thus, they connect the interior and exterior of a cell. All molecules bind their specific receptor or ligand, and this binding leads to a conformational change in the extracellular domain. All CAMs are attached to an intracellular molecule, which affects the function of the cell through the "second messenger pathway", producing changes in the cytoskeleton or the chemical composition of the cell. There are six families of CAMs; the immunoglobulin-like superfamily, the cadherins, the integrins, the receptor protein tyrosine phosphatases, the selectins, and the hyaluronate receptors. For information on each of their features, ligands and functions see the review by Freemont. ${ }^{1}$ CAMs can modulate disease processes, whether they are expressed normally or not. ${ }^{2}$ The role of CAMs or their ligands in abnormal processes occurs either as part of a physiological response to a pathological event - for example, inflammation or infection-or as part of the pathological process itself. ${ }^{1}$

Microorganisms have developed various strategies to subvert host defences and permit their particular lifestyle, among which several general themes have emerged. To enable succinct and meaningful documentation of particular microbial-CAM interactions under the headings below, I will first outline some general concepts and their relation to microbial pathogenesis.

Current and relevant topics in microbial pathogenesis Four types of secretion in Gram negative bacteria have been documented: types I, II, III, and IV. ${ }^{3}$ Type I is sec independent and is exemplified by the secretion of $\alpha$-haemolysin by Escherichia coli; it secretes effector proteins across the inner membrane, periplasm, and outer membrane in a one step process. Type II secretion is sec dependent and secretes effector 
proteins across the inner membrane into the periplasm using the general secretory pathway $(\mathrm{GSP})^{4}$; in the periplasm, the C-terminal sequence is removed and the protein is then secreted across the outer membrane by a complex of 12 or more proteins; known as the terminal branch of the GSP. The best studied example of type II secretion is the pullulanase (pulA) enzyme of Klebsiella oxytoca. ${ }^{4}$ Type III secretion occurs on host cell contact, and facilitates the translocation of effector molecules directly into the host cell cytoplasm. Type III systems are thought to be direct descendants of the flagellar assembly and consist of 20 or more proteins, which span the cell envelope. Type III systems are crucial for virulence in various organisms including Salmonella spp, Shigella spp, enteropathogenic $E$ coli (EPEC), and Bordetella spp. ${ }^{3}$ Effector proteins are targeted for type III secretion by the $\mathrm{N}$-terminal sequence of their encoding $\mathrm{mRNA}$ molecule. ${ }^{5}$ Type IV secretion occurs in various species and is responsible for secretion of - for example, Bordetella pertussis P.69 pertactin and the serum resistance protein, brkA. Transport across the inner membrane, periplasm, and outer membrane probably occurs in three separate stages with N-terminal and C-terminal processing of the transported protein. $^{6}$

CELLULAR MICROBIOLOGY

Microorganisms depend on their ability to subvert and subjugate eukaryotic host cells for their pathogenesis, and knowledge of eukaryotic cell physiology is becoming increasingly relevant to understanding microbial pathogenesis. ${ }^{7}$ Examples include viral adhesion/invasion and bacterial type III secretion systems, which facilitate bacterial internalisation and persistence. Pedestal formation in EPEC infection and phagocytosis are both mediated by cellular GTPases (Rho, Rac, and Cdc42), which are molecular switches for control of signal transduction pathways, linking membrane receptors to mitogen activated protein kinase and the actin cytoskeleton in various cell types.

RTX (repeats in toxin) toxins-for example, $E$ coli $\alpha$-haemolysin (hlyA), bind to lymphocyte function associated antigen 1 (LFA-1), a $\beta_{2}$ integrin (CD11a/CD18), ${ }^{8}$ causing pore formation and cytolysis. Several studies suggest that RTX toxins kill target cells by apoptosis.
Host defences are frequently responsible for disease manifestations, either directly in the case of the early response of plants to plant pathogens, or indirectly in the case of the utilisation of a particular pathway of phagocytosis that lacks a respiratory burst and enables intracellular survival in humans. Phagocytosis is an important host defence and in macrophages it is mediated by at least two receptors: complement receptor 3 (CR3), a $\beta_{2}$ integrin, and the immunoglobulin receptor $(\mathrm{Fc} \gamma \mathrm{R})$. CR3 consists of a $165 \mathrm{kDa} \alpha$ subunit (CD11b) and an $85 \mathrm{kDa} \beta$ subunit (CD18). Rho, Rac, and Cdc42 are GTPases that act as molecular switches in the reorganisation of the actin cytoskeleton, and the profile of their involvement depends on the particular phagocytic mechanism. ${ }^{9}$ Immunoglobulin dependent uptake (type I phagocytosis) requires Cdc42 and Rac and involves pseudopod extension, membrane ruffling, a respiratory burst, and an inflammatory reponse. CR3 dependent uptake (type II phagocytosis) is mediated by CR3, requires only Rho, and occurs without a respiratory burst. ${ }^{10} 11$ Differential GTPase involvement between the two types of phagocytosis probably determines the physiological differences between Fc $\gamma \mathrm{R}$ and CR3 mediated phagocytosis. $^{12} 13$

The purpose of this review is to document the interaction of eukaryotic CAMs and microorganisms in the context of: (1) the microbe in its strategy to gain access to and cause disease in the host, and (2) the host in its strategy to defend itself against infection. These aspects will be dealt with in this order.

\section{Microbial pathogenesis facilitated by CAMs}

In general, the interaction of microbes with eukaryotic CAMs can be divided arbitrarily into those interactions mediated by microbial molecules that remain associated with the prokaryotic or eukaryotic cell envelope, and those mediated by secreted microbial products and toxins.

\section{PROTOZOA}

Table 1 summarises the interactions of eukaryotic CAMs with protozoa. Erythrocytes infected with the malaria parasite, Plasmodium falciparum, sequester in deep tissues by binding to endothelial cells. This favours parasite

Table 1 Protozoa and fungi that interact with eukaryotic cell adhesion molecules (CAMs) during their pathogenesis

\begin{tabular}{|c|c|c|c|c|}
\hline Protozoan/fungus & Microbial molecules & Eukaryotic CAM & Role in pathogenesis & Refs \\
\hline Plasmodium falciparum & $\begin{array}{l}\text { PfEMP-1, erythrocyte band } 3 \text { related } \\
\text { adhesin, sequestrin, and break point open } \\
\text { reading frame }\end{array}$ & $\begin{array}{l}\text { Endothelial CD36, } \\
\text { ICAM-1, ELAM-1, } \\
\text { VCAM-1 }\end{array}$ & $\begin{array}{l}\text { Sequestration of infected RBCs in deep tissues by } \\
\text { endothelial cell binding; probably responsible for } \\
\text { cerebral malaria }\end{array}$ & $15-18$ \\
\hline Leishmania major & & CR3 (a $\beta_{2}$ integrin) & $\begin{array}{l}\text { Mediates CR } 3 \text { phagocytosis with reduced or absent } \\
\text { respiratory burst }\end{array}$ & 19 \\
\hline Entamoeba histolytica & $170 \mathrm{kDa} \mathrm{Gal} / \mathrm{GalNAc}$ lectin & $?$ & $\begin{array}{l}\text { Lectin similar to } \beta_{2} \text { integrin and probably regulates } \\
\text { integrin expression }\end{array}$ & 20 \\
\hline Candida albicans & INT1 $\left(\alpha_{M} / \alpha_{x}\right.$ integrin-like $)$ & - & $\begin{array}{l}\text { Int } 1 \text { has homology to human integrins and is crucial } \\
\text { for adhesion, hyphal growth, and pathogenicity }\end{array}$ & 21,22 \\
\hline Candida tropicalis & $\beta_{1}$ Integrin-like protein & & Adhesion & 23 \\
\hline Yeasts & & CR3 (a $\beta_{2}$ integrin) & CR3 phagocytosis & 24 \\
\hline Histoplasma capsulatum & ? & CR3 (a $\beta_{2}$ integrin) & CR3 phagocytosis & 25,26 \\
\hline Pneumocystis carinii & Gp120 (integrin-like protein) & $? \alpha$ Integrin subunit & $\begin{array}{l}\text { Interaction of gp } 120 \text { with A549 cells upregulates host } \\
\text { cell } \alpha_{5} \text { integrin expression }\end{array}$ & 27 \\
\hline
\end{tabular}

CR3, complement receptor 3; ELAM-1, endothelial leucocyte adhesion molecule 1; ICAM-1, intercellular adhesion molecule 1; PfEMP-1, Plasmodium falciparum erythrocyte membrane protein 1 ; VCAM-1, vascular cell adhesion molecule 1 . 
growth, evasion of host defences, and occlusion of the microcirculation leading to hypoxia and lactic acidosis, which together are probably responsible for cerebral malaria. ${ }^{14}$ Several CAMs on endothelial and other cells mediate the interaction with infected erythrocytes, including CD $36,{ }^{15}{ }^{16}$ intercellular cell adhesion molecule 1 (ICAM-1), ${ }^{17}$ endothelial leucocyte adhesion molecule 1 (ELAM-1), and vascular cell adhesion molecule 1 (VCAM-1). ${ }^{18}$

Leishmania major, the cause of leishmaniasis, is dependent for its pathogenesis on an intracellular lifestyle in the macrophage. The promastigote binds to CR3 and is phagocytosed by a type II pathway. ${ }^{19}$

Entamoeba histolytica kills host cells by adhering via a $170 \mathrm{kDa}$ Gal/GalNAc lectin on its surface. This molecule contains a cytoplasmic domain with similarity to the $\beta_{2}$ integrin motif, a crucial regulator of integrin activities in other systems mediated by inside out signalling. ${ }^{20}$

FUNGI

Table 1 summarises interactions of eukaryotic CAMs with fungi. Fibronectin receptors consisting of integrin-like proteins have been identified in Candida albicans and Candida tropicalis using various approaches, including monoclonal and polyclonal antibodies to $\alpha_{5} \beta_{1}$ integrins. $^{2328} 29$ The $C$ albicans INT1 gene encodes a surface protein that has $18 \%$ amino acid identity with the ligand binding (I) domain of the human $\alpha_{\mathrm{M}}$ integrin, and is necessary for adhesion, filamentous growth, and virulence. ${ }^{2122}$ However, proteins other than integrins may be involved because RGD motif (Arg-Gly-Asp) deletion in recombinant fibronectin does not decrease adherence. ${ }^{27}$ Yeasts also bind CR3 and are thus phagocytosed by macrophages by a type II pathway. ${ }^{24}$

Histoplasma capsulatum is a dimorphic, facultative intracellular fungus causing a broad spectrum of disease, including disseminated disease in the immunocompromised host. ${ }^{25}$ Histoplasma capsulatum yeasts and microconidia bind to macrophage CR3, mediating phagocytosis by a type II pathway, with a reduced or absent respiratory burst, ${ }^{25}$ and also bind to LFA-1 (CD11a) and p150,95 (CD11c). ${ }^{26}{ }^{30}$ However, the fungal ligand(s) are unknown at present. The organism multiplies within the macrophage phagosome by controlling the intraphagosomal environment and is then disseminated throughout the host. ${ }^{25}$

Pneumocystis carinii recognises ECM proteins such as fibronectin, vitronectin, and laminin on alveolar epithelial cells. Pneumocystis carinii encodes gp120, a membrane glycoprotein, which binds fibronectin in the presence of divalent cations, and this binding is inhibited by RGDS (Arg-Gly-Asp-Ser) from the fibronectin binding domain. Binding of gp120 to A549 pulmonary epithelial cells upregulates eukaryotic $\alpha_{5}$ integrins. ${ }^{27}$ These data suggest that an $\alpha$ integrin on the host cell interacts with a $\beta$ integrin on the microbial surface to produce an integrin heterodimer.
BACTERIA

Table 2 summarises interactions of eukaryotic CAMs with bacteria. Staphylococcus aureus and Streptococcus pyogenes produce various proteins of the superantigen family that bind specifically to the $\mathrm{V} \beta$ chains of the $\mathrm{T}$ cell receptor with high affinity, activating larger numbers of $T$ cells than processed antigens and resulting in massive cytokine release. ${ }^{31}$ Several clinical syndromes have been linked with superantigens such as food poisoning, toxic shock syndrome, and Kawasaki syndrome. ${ }^{31}$ Bacterial superantigens implicated in human disease include toxic shock syndrome toxin 1 (TSST-1), staphylococcal enterotoxin A (SEA), staphylococcal enterotoxin B (SEB), staphylococcal enterotoxin C (SEC), and streptococcal pyrogenic exotoxin A (SpeA). Released cytokines upregulate vascular and neutrophil adhesion molecules, leading to neutrophil influx. Leucocyte recruitment occurs through sequential involvement of different CAM families: selectins (E, $\mathrm{P}$, and L), integrins $\left(\alpha_{4}, \beta_{1}, \beta_{2}\right)$, and members of the immunoglobulin superfamily (ICAM-1, ICAM-2, and VCAM). ${ }^{32-35}$ Streptococcus pyogenes pyrogenic exotoxin $\mathrm{B}(\mathrm{SpeB})$ is a crucial virulence factor for invasive disease. A variant of SpeB, SpeB2, produced by all isolates of the virulent $\mathrm{M} 1$ serotype, contains an RGD sequence that mediates binding to $\alpha_{\mathrm{v}} \beta_{3}$ or $\alpha_{2 \mathrm{~b}} \beta_{3}$ integrins on endothelial cells and platelets, respectively. ${ }^{36}$

Mycobacterium tuberculosis is a facultative intracellular pathogen that enters alveolar macrophages, resists macrophage killing mechanisms, establishes a chronic infection, and disseminates via the blood and lymph, frequently in the absence of symptoms. The organism may bind to a number of receptors including the integrins, CR3, and CR4. CR3 binding leads to CR3 phagocytosis with an absent respiratory burst. Binding of macrophage CR3 also reduces interleukin 12 production, with a consequent suppression of macrophage responses and T helper type 1 (Th1) dependent cell mediated immunity. ${ }^{37}{ }^{38}$ On the other hand, CR4 binding results in phagocytosis with a respiratory burst. In addition, $M$ tuberculosis chaperonin 60 (heat shock protein 65) upregulates E selectin and ICAM-1 on vascular endothelium, ${ }^{39}$ and is thus proinflammatory and immunomodulatory, with the potential to induce tissue pathology.

Listeria monocytogenes is a Gram positive bacillus capable of intracellular replication in enterocytes, fibroblasts, dendritic cells, and macrophages. The normal route of infection is via the intestinal epithelial $M$ cells of the Peyer's patches, followed by basolateral invasion of enterocytes, and dissemination by blood and lymphatics to other tissues. Bacterial internalin A (InlA), a cell wall associated protein, binds E-cadherin on epithelial cells and is essential for internalisation. ${ }^{40}$ Internalin B (InlB) is required for entry into hepatocytes but its receptor is unknown. ${ }^{41}$ InlA and InlB contain leucine rich repeats and are members of a superfamily of leucine rich repeat containing proteins that are found only in pathogenic bacteria-for example, Shigella flexneri ipaH, 
Table 2 Bacteria that interact with eukaryotic cell adhesion molecules (CAMs) during their pathogenesis

\begin{tabular}{|c|c|c|c|c|}
\hline Bacterium & Bacterial molecule & Eukaryotic $C A M$ & Role in pathogenesis & Refs \\
\hline Staphylococcus aureus & TSST-1, SEA, SEB, SEC & $\begin{array}{l}\text { P, E, L selectins, } \alpha_{4}, \beta_{1}, \beta_{2} \text { integrins, ICAM- } 1 \text {, } \\
2 \text {, VCAM }\end{array}$ & Mitogenic with massive cytokine release & $32-35$ \\
\hline \multirow[t]{2}{*}{ Streptococcus pyogenes } & SpeA & $\begin{array}{l}\text { P, E, L selectins, } \alpha_{4}, \beta_{1}, \beta_{2} \text { integrins, ICAM-1, } \\
2 \text {, VCAM }\end{array}$ & Mitogenic with massive cytokine release & 31 \\
\hline & SpeB & $\alpha_{v} \beta_{3}+\alpha_{2 b} \beta_{3}$ Integrins & $\begin{array}{l}\text { RGD mediated adhesion to endothelium and } \\
\text { platelets }\end{array}$ & 36 \\
\hline \multirow[t]{3}{*}{ Mycobacterium tuberculosis } & & CR3 ( $\beta_{2}$ integrin CD11b/CD18) & CR3 phagocytosis without $\mathrm{O}_{2}$ burst & 38 \\
\hline & & CR4 $\left(\beta_{2}\right.$ integrin CD11c/CD18) & CR4 phagocytosis with $\mathrm{O}_{2}$ burst & 38 \\
\hline & Chaperonin 60 (hsp65) & $\begin{array}{l}\text { Upregulation of E selectin and ICAM-1 on } \\
\text { vascular endothelium }\end{array}$ & Proinflammatory and immunomodulatory & 39 \\
\hline \multirow[t]{2}{*}{ Listeria monocytogenes } & Internalin $\mathrm{A}$ & E-cadherin & Invasion of epithelial (including $M$ ) cells & 40 \\
\hline & Internalin B & $?$ & $\begin{array}{l}\text { Invasion of epithelial (including } M \text { ) cells and } \\
\text { hepatocytes }\end{array}$ & 41 \\
\hline \multirow[t]{2}{*}{ Escherichia coli } & Antigen 43 & Integrins & RGD motif; secreted by type IV pathway & 42 \\
\hline & $\alpha$-Haemolysin & $\beta_{2}$ Integrin (LFA-1) CD11a/CD18 & Adherence, pore formation, and cytolysis & 8 \\
\hline Enteropathogenic $E$ coli (EPEC) & Intimin & Tir $+\beta$ integrins & Adherence and pathogenesis of $\mathrm{A} / \mathrm{E}$ lesion & $43-45$ \\
\hline Shigella flexneri & IpaBCD complex & $\alpha_{5} \beta_{1}$ Integrin & Uptake into $\mathrm{CHO}$ cells & 46,47 \\
\hline Yersinia pseudotuberculosis & Invasin & $\beta_{1}$ Integrins & Bacterial translocation via $M$ cells & $48-50$ \\
\hline Serratia marcescens & Ssp & Integrins & RGD motif; secreted by type IV pathway & 51 \\
\hline Legionella pneumophila & & CR3 integrin & Adhesion and phagocytosis & 52 \\
\hline \multirow{4}{*}{ Neisseria spp. } & Opa & HSPG & Invasion of Chang epithelial cells & 53,54 \\
\hline & Opa & HSPG $+\alpha_{\mathrm{v}} \beta_{5}$ integrin & Invasion of $\mathrm{HeLa} / \mathrm{CHO}$ cells & 55,56 \\
\hline & Opa & HSPG $+\alpha_{5} \beta_{1}$ integrin & Invasion of HEp-2 cells & 57 \\
\hline & Opa & CD66 & Invasion of neutrophils & 58 \\
\hline \multirow[t]{6}{*}{ Bordetella pertussis } & fimD & Integrin VLA-5 & Adhesion & 59 \\
\hline & PT & $\begin{array}{l}\text { CR3 integrin, Mac-1 integrin receptor } \\
\text { (CD11b/CD18) }\end{array}$ & $\begin{array}{l}\text { CR3 upregulation as a result of selectin } \\
\text { mimicry. Monocyte cell adhesion }\end{array}$ & $\begin{array}{l}60,61 \\
62\end{array}$ \\
\hline & FHA & Integrins & Adhesion and invasion via CR3 phagocytosis & 61,63 \\
\hline & P.69 pertactin & Integrins & $\begin{array}{l}\text { Adherence may be mediated by RGD motif; } \\
\text { secreted by type IV pathway }\end{array}$ & 64 \\
\hline & BrkA & Integrins & $\begin{array}{l}\text { RGD motif; secreted by type IV pathway; } \\
\text { mediates serum resistance }\end{array}$ & 65 \\
\hline & TcfA & Integrins & $\begin{array}{l}\text { RGD motif; secreted by type IV pathway; } \\
\text { contributes to tracheal colonisation }\end{array}$ & 66 \\
\hline Bordetella parapertussis & P.70 & Integrins & RGD motif; secreted by type IV pathway & 67 \\
\hline Bordetella bronchiseptica & P.68 & Integrins & RGD motif; secreted by type IV pathway & 68 \\
\hline Bartonella bacilliformis & $?$ & $\alpha_{5} \beta_{1}$ Integrin & Bacterial translocation into Hep2 cells & 69 \\
\hline Pasteurella haemolytica & Leucotoxin & $\beta_{2}$ Integrin (LFA-1) (CD1 1a/CD18) & $\begin{array}{l}\text { RTX toxin binding, pore formation, and } \\
\text { apoptosis }\end{array}$ & 70 \\
\hline Borrelia burgdorferi & & CR3 integrin, $\alpha_{11} \beta_{3}$ integrin & CR3 phagocytosis. Adhesion to platelets & 7172 \\
\hline Prohpyromonas gingivalis & LPS & Upregulation of $\mathrm{E}$ and $\mathrm{P}$ selectins & ?Ability to colonise and cause chronic disease & 73 \\
\hline Actinobacillus & $?$ & Integrins & Invasion & 74 \\
\hline actinomycetemcomitans & Leucotoxin & $\beta_{2}$ Integrin (LFA-1) CD1 1a/CD18 & $\begin{array}{l}\text { RTX toxin binding, pore formation, and } \\
\text { cytolysis }\end{array}$ & 8 \\
\hline Mycoplasma penetrans & Membrane lipoprotein & CD18 ( $\beta$ subunit of $\beta_{2}$ integrins) & Mitogenicity & 75,76 \\
\hline
\end{tabular}

A/E attaching and effacing; CHO, chinese hamster ovary; CR3, complement receptor 3; FHA, filamentous haemagglutinin; fimD, minor fimbrial subunit D; hsp65, heat shock protein 65; HSPG, heparan sulphate proteoglycan; ICAM-1, intercellular adhesion molecule 1; LFA, lymphocyte function associated antigen 1; LPS, lipopolysaccharide; PT, pertussis toxin; SEA, staphylococcal enterotoxin A; SpeA, streptococcal pyrogenic exotoxin A; tcfA, tracheal colonisation factor A; 1; Tir, translocated intimin receptor; TSST-1, toxic shock syndrome toxin 1; VCAM-1, vascular cell adhesion molecule.

Yersinia pestis yopM, B pertussis filamentous haemagglutinin (FHA), and Treponema pallidum TpLRR. ${ }^{77-80}$ The leucine rich repeat region of InlA mediates binding to caco-2 cells. ${ }^{81}$

Escherichia coli hlyA is an RTX toxin that kills human immune cells. It is secreted by a type I pathway and is localised to the surface of lymphocytes by binding to LFA-1, a $\beta_{2}$ integrin $(\mathrm{CD} 11 \mathrm{a} / \mathrm{CD} 18) .{ }^{8} \mathrm{EPEC}$ is the prototype of a family of pathogens that causes "attaching and effacing" lesions, characterised by intimate adherence between bacteria and epithelial cells and effacement of intestinal microvilli. ${ }^{43} \mathrm{Sev}-$ eral proteins, designated Esps, translocated by a type III system, are essential for this activity. Adherence was shown to occur as a result of the binding of a bacterial imtimin protein to a "eukaryotic" receptor. However, it has been discovered recently that the host receptor is in fact a bacterial product whose transfer into host cells is dependent on the type III system and two other proteins (espA and espB), and it has been renamed Tir (translocated intimin receptor) or espE. In addition, $\beta_{1}$ integrin may act as an alternative receptor. ${ }^{43-45}$

Shigella flexneri, the cause of bacillary dysentery, enters epithelial cells by reorganising the actin cytoskeleton, a process requiring the Ipa proteins secreted by the type III system. ${ }^{46}$ The shigella IpaBCD complex has been shown to bind $\alpha_{5} \beta_{1}$ integrin, an interaction that appears to play an active role during entry. ${ }^{47}$ Because $\beta_{1}$ integrins can associate with the actin cytoskeleton via the C-terminus, this may mediate invasion. The fact that Rho, a small GTPase involved in focal adhesion formation, is required for this is consistent with this hypothesis. ${ }^{46}$

Yersinia pseudotuberculosis and Yersinia enterocolitica cause food poisoning and, after ingestion, translocate across the intestinal epithelial barrier via the $M$ cells of Peyer's patches. $M$ cells are a major site of invasion of bacteria at least during the early stages of infection. In the mouse, $\mathrm{M}$ cells are invaded by both $Y$ pseudotuberculosis ${ }^{48}$ and $Y$ enterocolitica. ${ }^{81}$ Yersinia pseudotuberculosis invasin protein attaches to $\beta_{1}$ integrins on $M$ cells, leading to invasion. ${ }^{48-50}$ Murine Peyer's patch $M$ cells express $\beta_{1}$ integrins but enterocytes do not. ${ }^{48}$ Internalisation requires high affinity binding and focal adhesion kinase activity ${ }^{82}$ Invasin also promotes binding to and activation of $\mathrm{B}$ lymphocytes via $\beta_{1}$ integrin. ${ }^{83}$

Legionella pneumophila is an aerobic Gram negative bacillus, which causes Legionnaire's 
A

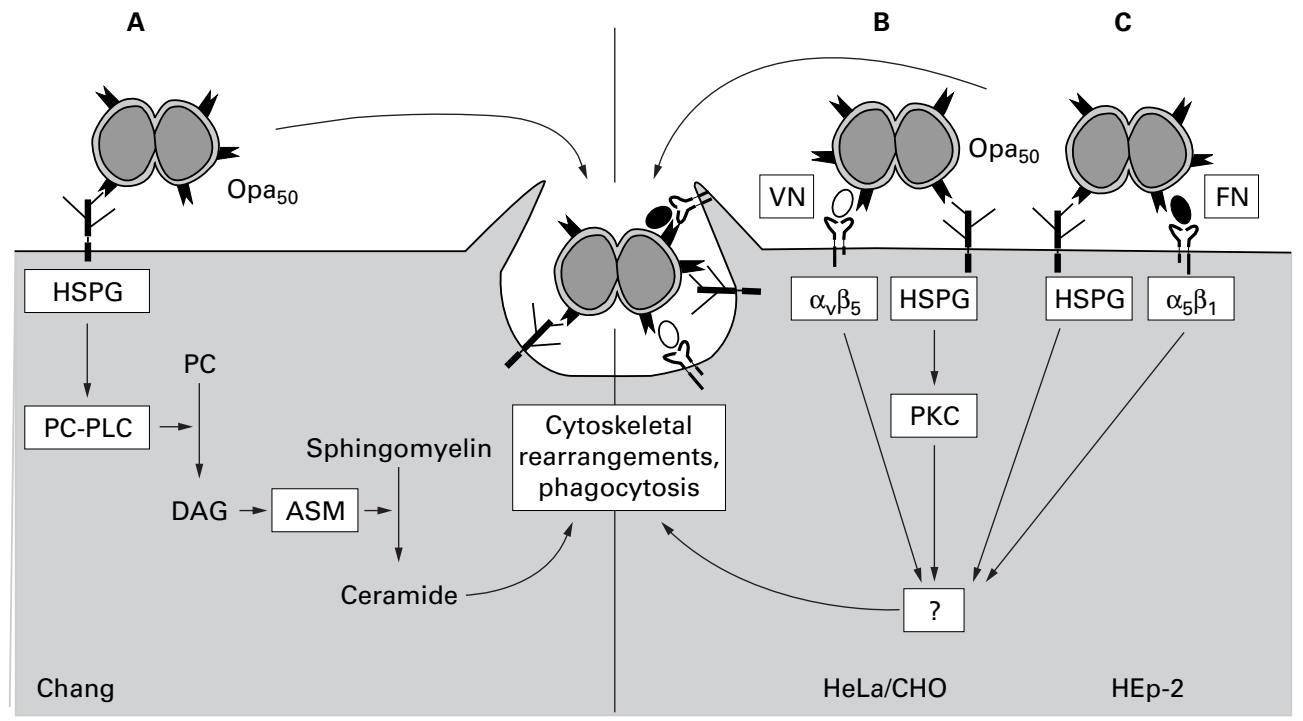

Figure 1 Mechanisms of $O p a_{50}$ mediated internalisation into different epithelial cell lines. (a) In Chang conjunctiva epithelial cells, heparan sulphate proteoglycan (HSPG) dependent internalisation involves the activation of phosphatidylcholine dependent phospholipase C (PC-PLC), which results in the generation of the second messenger diacylglycerol (DAG) from phosphatidylcholine (PC).DAG activates the acidic sphingomyelinase (ASM), which then generates ceramide from sphingomyelin. By an unknown process, ceramide is implicated in mediating cytoskeletal reorganisation and bacterial uptake by a mechanism that resembles conventional phagocytosis. (b) Efficient bacterial uptake into HeLa cervical carcinoma cells and Chinese hamster ovary (CHO) cells also relies on the ability of $\mathrm{Opa}_{50}$ to mediate binding to the extracellular matrix protein, vitronectin $(V N)$ and thereby to co-ligate HSPGs and $\alpha_{v}$ integrin vitronectin (VN) receptors, including $\alpha_{z} \beta_{5}$. This internatisation process appears to be dependent on the activity of protein kinase $C$ (PKC). (c) In HEp-2 larynx carcinoma cells, efficient bacterial uptake of Opa ${ }_{50}$ expressing gonococci requires binding of the extracellular matrix protein, fibronectin (FN), which results in a co-ligation of HSPGs and the FN receptor $\alpha_{s} \beta_{1}$ integrin: however, the mechanism of entry is still poorly understood. Reproduced from Dehio et al, ${ }^{58}$ with the permission of Elsevier Science, Oxford, UK.

disease in predisposed individuals. The organism has an intracellular lifestyle and replicates in alveolar macrophages after opsonin dependent, CR3 mediated phagocytosis mediated by actin polymerisation at the site of entry, which is dependent on tyrosine phosphorylation of various host proteins. ${ }^{52}$

Neisseria gonorrhoeae and Neisseria meningitidis colonise the human host, and this can either be asymptomatic or lead to the severe local or systemic inflammatory responses that characterise gonorrhoea and meningococcal meningitis, respectively. Primary attachment is mediated by bacterial pili, with a more intimate attachment mediated by the bacterial opacity associated (Opa) proteins, originally identified because their expression results in a change of colony opacity and colour as a result of bacterial aggregation. ${ }^{58}$ Opa proteins utilise heparan sulphate proteoglycan (HSPG) in Chang conjunctiva cells for intimate adhesion and invasion..$^{53}$ An alternate pathway of HSPG dependent invasion exists in HeLa and HEp-2 cells, which is triggered in the presence of serum. The serum factor is vitronectin, which binds specifically to Opa expressing gonococci, stimulating bacterial uptake in a $\alpha_{\mathrm{v}} \beta_{5}$ integrin dependent manner (fig 1)..$^{55-57}$ Opa proteins also bind CD66 on neutrophils, an interaction that mediates uptake. ${ }^{58}$

Bordetella pertussis is a small Gram negative bacillus, which after aerosol transmission by respiratory droplets causes whooping cough in children and adults. The organism produces several adhesins and toxins that are coordinately regulated by the products of the BvgAS locus. Several of these virulence factors are dependent on host cell integrins for their pathogenesis. The minor fimbrial subunit, fimD, has been shown to bind to integrin VLA-5 (very large antigen 5) and heparin, an interaction that is important for colonisation of the mouse respiratory tract. ${ }^{59}$ Bacterial uptake into alveolar macrophages relies on selectin and integrin mimicry by PT and FHA, respectively. ${ }^{84}$ Pertussis toxin S2 and S3 treatment of human macrophages upregulates CR3 as a result of selectin mimicry ${ }^{6061}$ (selectins have been shown to upregulate integrins). ${ }^{63}$ Secreted FHA, which has binding sites for both integrins and the bacterial surface itself, coats the bacteria and mediates CR3 binding and phagocytosis, permitting avoidance of the respiratory burst and intracellular multiplication. ${ }^{61}$ Pertussis toxin has also been shown to bind the Mac-1 integrin receptor (CD11b/CD18, ) leading to tyrosine phosphorylation and monocytic cell adhesion in serum. ${ }^{62}$

Several proteins secreted by a type IV pathway (autotransporters) contain RGD motifs, which are associated with attachment to mammalian cells via binding of $\beta$ integrins on the plasma membrane. ${ }^{85}$ These include $B$ pertussis brkA, ${ }^{65}$ P.69 pertactin, ${ }^{64}$ and tcfA, ${ }^{66}$ Bordetella parapertussis P.70, ${ }^{67}$ Bordetella bronchiseptica P.68, ${ }^{68}$ E coli antigen $43,{ }^{42}$ and Serratia marcescens ssp. ${ }^{51}$ Most RGD containing autotransporters contain two RGD sites, one within the passenger domain and one within the $\beta$ domain. ${ }^{6}$ The importance of these RGD motifs has yet to be determined, but they probably play a role in the adhesion of $B$ pertussis P.69 pertactin. ${ }^{86}$

Bartonella bacilliformis is a fastidious Gram negative bacillus, transmitted by the sandfly, which causes bartonellosis. ${ }^{87}$ It is a facultative 
Table 3 Viruses that interact with eukaryotic cell adhesion molecules (CAMs) during their pathogenesis

\begin{tabular}{|c|c|c|c|}
\hline Virus & Eukaryotic CAM & Role in pathogenesis & Refs \\
\hline Poliovirus $1-3$ & PVR (Ig-like) & Adhesion and invasion & 89 \\
\hline Coxsackie virus A13, A18, A21 & ICAM-1 & Adhesion and invasion & 92 \\
\hline Coxsackie virus A9 & $\alpha_{v} \beta_{3}$ Integrins & Adhesion and invasion & 88 \\
\hline Coxsackie virus B1-6 & CAR (Ig-like) & Adhesion and invasion & 99 \\
\hline Coxsackie virus B1, B3, B5 & DAF; $\alpha_{v} \beta_{6}$ integrins & Adhesion and invasion & 95,96 \\
\hline Adenovirus & CAR (Ig-like) & Adhesion and invasion & 97 \\
\hline Echovirus 1 & $\alpha_{2} \beta_{1}$ Integrin & Adhesion and invasion & 98 \\
\hline Echovirus $3,6,7,11-13,20,21,24,29,33$ & DAF & Adhesion and invasion & $98-100$ \\
\hline Echovirus 22 & $\alpha_{4} \beta_{3}$ Integrin & Adhesion and invasion & 101,102 \\
\hline Hepatitis A (enterovirus 72; HAV) & HAVcr-1 (Ig-like) & Adhesion and invasion & 103 \\
\hline Rhinovirus major gp (91 serotypes) & ICAM-1 & Adhesion and invasion & 93,94 \\
\hline Foot and mouth disease virus & $\alpha_{\mathrm{v}} \beta_{3}$ Integrin & Adhesion and invasion & 91 \\
\hline Encephalomyocarditis virus & VCAM-1 & Adhesion and invasion & 104 \\
\hline \multirow[t]{2}{*}{ HIV-1 } & $\mathrm{CD} 4$ & Adhesion and invasion of $\mathrm{T}$ lymphocytes & 105 \\
\hline & PMN CD11a, CD11b, L selectin & HIV related PMN dysfunction & 106 \\
\hline Human herpesvirus-7 & $\mathrm{CD} 4$ & Adhesion and invasion of T lymphocytes; downregulation of CD4 & 107,108 \\
\hline Cytomegalovirus & $\alpha_{1} \beta_{1}$ Integrin & Immune evasion by downregulation of $\alpha_{1} \beta_{1}$ integrin on fibroblasts & 109 \\
\hline Adeno associated virus (AAV) & $\alpha_{\mathrm{v}} \beta_{5}$ Integrin & Adhesion and invasion & 110 \\
\hline Hantaviruses & $\alpha_{3} \beta_{3}$ Integrins & Adhesion and invasion of platelets and endothelial cells & 90 \\
\hline Bovine leukaemia virus & CD $11 \mathrm{c}$ integrin & $\begin{array}{l}\text { Pathogenesis of lymphocytosis involves upregulation of CD11c on } \\
\mathrm{B} \text { and T lymphocytes }\end{array}$ & 111 \\
\hline
\end{tabular}

CAR, coxsackie adenovirus receptor; DAF, decay accelerating factor; HIV, human immunodeficency virus; ICAM-1, intercellular adhesion molecule 1; PMN, polymorphonuclear leucocyte; PVR, poliovirus receptor; VCAM-1, vascular cell adhesion molecule 1.

intracellular pathogen that binds to $\alpha_{5} \beta_{1}$ integrin on human epithelial cells, with the induction of tyrosine phosphorylation of several host proteins and subsequent uptake. ${ }^{69}$

Pasteurella haemolytica is a Gram negative bacillus that produces a leucotoxin that kills bovine immune cells and causes bovine pasteurellosis. The leucotoxin is a member of the RTX family of pore forming toxins, which are thought to effect cellular killing by induction of apoptosis. An early step for induction of apoptosis is the binding of leucotoxin to $\beta_{2}$ integrin on bovine leucocytes. ${ }^{70}$

The Lyme disease spirochaete, Borrelia burgdorferi, is transmitted by the bite of an infected tick, causing localised infection, which disseminates, leading to chronicity. It is a facultative intracellular pathogen, and binds CR3 leading to CR3 phagocytosis. ${ }^{71}$ The organism also binds platelets via $\alpha_{1} \beta_{3}$ integrin, which may be important in dissemination. ${ }^{72}$

Porphyromonas gingivalis is an anaerobic Gram negative bacillus crucial for the development of adult periodontitis. Porphyromonas gingivalis lipopolysaccharide (LPS) has been shown to upregulate $\mathrm{E}$ selectins and $\mathrm{P}$ selectins, among other activities, ${ }^{73}$ and this might be important in colonisation and pathogenicity. Actinobacillus actinomycetemcomitans, another coloniser of the gingival sulcus and a periodontal pathogen, enters host cells through ruffled apertures by an actin dependent mechanism, which may depend on host cell integrins for internalisation. ${ }^{74}$ Actinobacillus actinomycetemcomitans also produces a leucotoxin that is a member of the RTX family of toxins. The leucotoxin binds LFA-1, a $\beta_{2}$ integrin, on leucocytes, resulting in pore formation and cytolysis. $^{8}$

Mycoplasmas are minute prokaryotes without a cell wall, which enter an appropriate host and multiply and survive for extended periods of time. Mycoplasmas stimulate lymphocytes in a non-specific polyclonal manner. For example, Mycoplasma penetrans possesses several $\mathrm{B}$ and $\mathrm{T}$ cell mitogens, including a membrane lipoprotein whose activity is inhibited in a dose dependent manner by a monoclonal antibody against $\mathrm{CD} 18$, the $\beta$ subunit of $\beta_{2}$ integrins. ${ }^{75}$ In addition, $\mathrm{Myco-}$ plasma arthritidis produces a superantigen. ${ }^{76}$

VIRUSES

Table 3 summarises interactions of eukaryotic CAMs with viruses. Replication of a virus begins with attachment to its receptor (a eukaryotic cell surface molecule), followed by entry of the virus into the cell, and there are many examples of the use of CAMs in viral pathogenesis. Picornaviruses utilise at least nine distinct receptors for cell entry. ${ }^{88}$ All three serotypes of poliovirus bind to the poliovirus receptor (PVR), which is a three immunoglobulin-like domain type I membrane glycoprotein, whose cellular function is unknown. ${ }^{89}$ At present, no other picornavirus is known to use this receptor. ${ }^{88}$ Coxsackie virus A9 (CVA9) uses the vitronectin receptor $\left(\alpha_{v} \beta_{3}\right.$ integrin), also used by hantaviruses ${ }^{90}$ and foot and mouth disease virus. ${ }^{91}$ CVA9 has an RGD integrin binding motif at the carboxyl end of VP1 (viral protein 1), and virus binding is blocked by RGD containing peptides; however, because trypsin mediated inactivation of this motif does not block infection of African green monkey cells, there may be an alternative receptor. ${ }^{88}$ ICAM-1 is used by coxsackie viruses $\mathrm{A} 13, \mathrm{~A} 18$, and $\mathrm{A} 21^{92}$ and the major group of rhinoviruses (91 serotypes). ${ }^{93} 94$ The coxsackie viruses, especially CVB3, may use decay accelerating factor (DAF) in association with $\alpha_{v} \beta_{6}$ integrin, ${ }^{95}{ }^{96}$ or the immunoglobulinlike coxsackievirus adenovirus receptor (CAR), also used by the adenoviruses. ${ }^{97}$ Echoviruses use $\alpha_{2} \beta_{1}$ integrin, ${ }^{98} \mathrm{DAF}^{98-100}$ or $\alpha_{\mathrm{v}} \beta_{3}$ integrin. $^{101} 102$ Hepatitis A (enterovirus 72; HAV) uses the HAV cellular receptor 1 (HAVcr-1), whose cellular function is unknown, although is known to be immunoglobulin and mucin-like. ${ }^{103}$ Encephalomyocarditis virus uses VCAM-1 for adhesion and invasion. $^{104}$

Human immunodeficiency virus 1 (HIV-1) gp120 binds CD4, a member of the immunoglobulin superfamily, on mature circulating $\mathrm{T}$ helper/inducer lymphocytes as a first step in 
Table 4 Human cell adhesion molecules (CAMs) mediating leucocyte-endothelial cell interaction during host defence against infection ${ }^{115}$

\begin{tabular}{|c|c|c|c|c|}
\hline Leucocyte receptor & Leucocyte distribution & Endothelial ligand & Expression & Function \\
\hline \multicolumn{5}{|l|}{ Selectins } \\
\hline L selectin (CD62L) & All leucocytes & GlyCAM-1 and others & Constitutive & Rolling \\
\hline \multicolumn{5}{|l|}{ Integrins } \\
\hline$\alpha_{1} \beta_{2}$ (Mac-1, Mo-1, CD11b/CD18) & Monocytes, PMN & ICAM-1, ?ICAM-2 & Induced by IFN- $\gamma$ and others & Firm adhesion \\
\hline$\alpha_{\mathrm{L}} \beta_{2}(\mathrm{LFA}-1, \mathrm{CD} 11 \mathrm{a} / \mathrm{CD} 18)$ & All leucocytes & ICAM-1 & Induced by IFN- $\gamma$ & Firm adhesion \\
\hline & & ICAM-2 & Constitutive & \\
\hline$\alpha_{4} \beta_{1}(\mathrm{CD} 49 \mathrm{~d} / \mathrm{CD} 29)$ & All leucocytes & VCAM-1 & Induced by TNF- $\alpha$ and others & Firm adhesion or rolling \\
\hline$\alpha_{4} \beta_{7}$ Lymphocytes & MAdCAM & ? & Rolling & \\
\hline$\alpha_{\mathrm{v}} \beta_{3}$ & Lymphocytes, PMN & PECAM (CD31) & Constitutive & Transmigration \\
\hline \multicolumn{5}{|l|}{ Immunoglobulin superfamily } \\
\hline IAP (CD47) & All leucocytes & ? & Constitutive & Transmigration \\
\hline PECAM (CD31) & PMN & PECAM ? $\alpha_{\mathrm{v}} \beta_{3}$ & Constitutive & Transmigration \\
\hline \multicolumn{5}{|l|}{ Others } \\
\hline PSGL-1 & PMN & P selectin (CD62P) & Constitutive & Rolling \\
\hline ESL & PMN & E selectin (CD62E) & Induced by IFN- $\gamma$ & Rolling \\
\hline $\mathrm{CD} 44$ & All leucocytes & Hyaluronate & Constitutive & ? \\
\hline
\end{tabular}

ESL, E selectin ligand; GlyCAM-1, glycosylation dependent cell adhesion molecule 1; IAP, integrin associated protein; ICAM-1, intercellular adhesion molecule 1; IFN- $\gamma$, interferon $\gamma$; LFA-1, lymphocyte function associated antigen 1; MAdCAM, mucosal addressin cell adhesion molecule; PECAM, platelet endothelial adhesion molecule; PSGL, P selectin glycoprotein ligand; PMN, polymorphonuclear leucocyte; TNF- $\alpha$, tumour necrosis factor $\alpha$; VCAM, vascular cell adhesion molecule 1.

infection. ${ }^{105}$ In addition, CD4-gp120 interaction is necessary for cell-cell spread of HIV. This led to early investigation of recombinant soluble CD4 (rsCD4) as an anti-HIV treatment. High dose intravenous rsCD4 abrogates viraemia in a dose dependent manner; however, the duration of the effect is limited by the pharmacokinetics of rsCD4. Although pharmacokinetics have been improved by combining $\mathrm{rsCD} 4$ with immunoglobulin molecules (rsCD4-IgG), therapeutic benefit in the treatment of established HIV infection has been limited. However, there may be some benefit in prophylaxis of perinatal and needle stick infections. ${ }^{112}$ In addition, dysregulated neutrophil function in HIV infection is mediated by integrins and selectins. ${ }^{106}$

Human herpesvirus 7 (HHV7) grows well in CD4 positive lymphocytes and also uses the CD4 molecule as its receptor. ${ }^{107} \mathrm{HHV} 7$ also downregulates expression of CD4 and, therefore, the use of its envelope has been suggested in anti-HIV treatment. ${ }^{108}$

Cytomegalovirus (CMV), another herpesvirus, achieves permanent coexistence with its hosts by establishing latent infection in specific "privileged" tissues to evade immune surveillance. ${ }^{113}$ Mechanisms to this end include the CMV mediated downregulation of $\alpha_{1} \beta_{1}$ integrin in human fibroblasts, ${ }^{109}$ and the possible production of a putative superantigen that is present on infected monocytes, leading to selective expansion of V $\beta$ T cell receptor bearing lymphocytes. ${ }^{114}$ Alternatively, this superantigen may be a human gene product transciptionally activated by CMV expression, which may induce active infection from the latent state. ${ }^{113}$

Adeno associated virus 2 (AAV-2), a ubiquitous human parvovirus, which is used as a vector in various experimental gene therapies, uses HSPG as a primary receptor, but is also dependent on $\alpha_{v} \beta_{5}$ integrin to increase susceptibility of cells to infection. ${ }^{110} \alpha_{\mathrm{v}} \beta_{5}$ Integrin is involved in facilitating virus internalisation, a finding that has relevance for human gene therapy.

Bovine leukaemia virus (BLV), human $\mathrm{T}$ lymphotropic virus 1 (HTLV-1), and HTLV-II belong to the same family of oncogenic retroviruses that causes spontaneous lym- phocyte proliferation. Infection with these viruses is associated with increased expression of lymphocyte integrins, CD11c and CD18. Lymphocyte dysregulation in spontaneous lymphocyte proliferation probably involves signalling through these lymphocyte surface molecules. ${ }^{111}$

\section{CAMs in the host defence against infection}

The cellular immune system is a potent force which, if controlled and directed correctly, is effective against an enemy and forms an appropriate host defence; however, if uncontrolled, it is ineffective against the enemy and can actually be harmful to the host itself. Therefore, leucocyte action must be held in check in the circulation, and discharged at the site of infection. This is achieved through the leucocyte adhesion molecules, which recognise areas of tissue damage and direct their own transendothelial migration into the tissues. Important in this process are integrins, selectins, and immunoglobulin-like superfamily members. ${ }^{115}$

\section{LEUCOCYTE ADHESION MOLECULES}

Leucocyte migration to sites of infection requires several separate adhesion events, namely: tissue damage recognition, endothelial interaction, transendothelial migration, and migration through the extracellular matrix to the site of infection. CAM families that mediate leucocyte and endothelial cell interaction and which are primarily responsible for these events include the integrins, selectins, and immunoglobulin superfamily. They recognise each other as a result of their affinities and their location on the plasma membrane. Table 4 summarises their expression and interactions. Because of the constitutive expression of certain leucocyte CAMs and the expression of certain other CAMs by the endothelial cells only at sites of inflammation, the leucocyte is always ready to recognise the endothelium at sites of infection.

Integrins exist in the membrane as heterodimers and function in cell-cell and cellmatrix interactions in almost all cells. ${ }^{116}$ Each heterodimer consists of an $\alpha$ and $\beta$ chain encoded by their respective genes. There are 14 known $\alpha$ genes and eight known $\beta$ genes, which 
can combine to express 22 different integrins. The integrins modulate ligand binding kinetics in response to environmental signals and facilitate the need of leucocytes for migration, flexibility of function, and rapid response. Several leucocyte integrins are crucial to leucocyte adhesion, rolling, and transmigration, such as $\alpha_{\mathrm{M}} \beta_{2}, \alpha_{\mathrm{L}} \beta_{2}, \alpha_{\mathrm{X}} \beta_{2}$, and $\alpha_{4} \beta_{7}$ (table 4 ).

Selectins are calcium dependent, and expressed on leucocytes and endothelial cells. ${ }^{117}$ L selectins are expressed constitutively on virtually all leucocytes and $\mathrm{E}$ selectins and $\mathrm{P}$ selectins are expressed on endothelial cells. E selectin is not expressed on resting endothelium but is expressed after stimulation by a number of cytokines released in response to inflammation, tissue damage, and immune responses. ${ }^{118} \mathrm{P}$ selectin is expressed constitutively in many endothelial cells; not at the plasma membrane, but in regulated secretory Wiebel-Palade bodies. ${ }^{119}{ }^{120}$ This stored P selectin is rapidly mobilised to the plasma membrane in response to inflammatory stimuli, such as thrombin or histamine, and is then recognised by circulating leucocytes. All known specific ligands for the selectins are mucins.

Immunoglobulin superfamily members mediate cell adhesion for a variety of different cell types. For example, on endothelial cells, ICAM-1 and ICAM-2 are recognised by leucocyte integrins; VCAM-1 is a ligand for $\alpha_{4} \beta_{1}$ integrin on monocytes and lymphocytes, and mucosal addressin CAM (MAdCAM) is recognised by $\alpha_{4} \beta_{7}$ and L-selectin on Peyer's patch lymphocytes, ${ }^{121} 122$ and has both integrin binding immunoglobulin domains and a selectin binding mucin domain. Two immunoglobulin superfamily members involved in leucocyte transendothelial migration are platelet endothelial adhesion molecule (PECAM) and integrin associated protein (IAP). PECAM is expressed at endothelial cell-cell junctions and on all leucocytes. IAP is present on fibroblasts, platelets, erythrocytes, neurones, epithelium, endothelium, and leucocytes. ${ }^{123} 124$ Both PECAM and IAP are expressed on leucocytes and endothelium and are probably involved in leucocyte transendothelial migration. ${ }^{125} 126$

\section{LEUCOCYTE TRANSENDOTHELIAL MIGRATION}

The current leucocyte-endothelial adhesion model involves three steps. ${ }^{34}$ In the first step, leucocytes are slowed in the circulation, most often by low affinity selectin-mucin interaction. This leads to leucocyte rolling along the vessel wall, with increased exposure of the leucocyte to the vessel environment, and thus increased sampling of signals from cytokines, chemoattractants, lipopolysaccharide, or abnormal homeostasis. Prevention of the rolling process severely impedes migration. Rolling leads to leucocyte activation as a result of stimulation of receptors, which include the serpentine family. ${ }^{127}$ Leucocyte adhesion deficiency (LAD) type II comprises a syndrome of mental retardation, short stature, and defective polymorphonuclear cell function caused by an absence of sialyl-Lewis-X, an essential part of selectin ligands, which results in greatly decreased leucocyte rolling. ${ }^{128-130}$

The second step is endothelial adhesion mediated by high avidity integrin activation, which for its efficient recruitment requires prior leucocyte rolling. This adhesion is inhibited by anti- $\beta_{2}$ integrin antibodies and is defective in LAD type I, a syndrome of delayed umbilical cord separation, and recurrent bacterial infections caused by a defect in polymorphonuclear cell migration and activation. ${ }^{131}$ LAD type $I$ is caused by a defect in the $\beta_{2}$ (CD18) gene resulting in a failure to express $\beta_{2}$ integrins. ${ }^{132}$

The third step is leucocyte transmigration through the intercellular junctions of the endothelium, requiring polymorphonuclear cell chemotaxis and endothelial cell signalling. Immunoglobulin superfamily members required for this step are PECAM-a (CD31) and IAP (CD47), which both interact with integrin $\alpha_{v} \beta_{3}{ }^{133}{ }^{134}$ It has been suggested that PECAM on tightly adherent leucocytes binds endothelial $\alpha_{v} \beta_{3}$, with a consequent loosening of cell-cell junctions, allowing the leucocytes to migrate through. ${ }^{135}$ Once they have left the vascular compartment, leucocytes migrate to sites of infection on extracellular matrix proteins.

LEUCOCYTE ACTIVATION AT SITES OF INFECTION Leucocytes at sites of infection and inflammation have a very different phenotype from those present in the circulation: they are metabolically active, highly adherent, and destructive. Many mediators can signal this phenotypic change, but among the most potent are the proteins of the ECM. This mechanism depends on $\beta_{3}$ integrin as the leucocyte receptor; called the leucocyte response integrin. ${ }^{136-138}$ IAP probably forms a complex with the leucocyte response integrin on the plasma membrane, a complex that acts as the signalling unit through which the ECM proteins mediate polymorphonuclear cell activation. Integrins also cooperate with other host defence receptors, such as Fc $\gamma \mathrm{R}$ and Mac-1. ${ }^{115}$

\section{Conclusion and future prospects}

In conclusion, eukaryotic CAMs are essential for the host defence against infection, and from present knowledge they are an integral facilitating factor in the pathogenesis of many protozoal, fungal, bacterial, and viral infections. Currently, the number of antibiotic options for treatment of infectious disease are limited because of the development of resistance. This has led to measures to preserve the usefulness of antibiotics, develop new classes of antibiotic, and develop alternative strategies for the treatment of infectious disease-for example, human recombinant antibodies, bacteriophage treatment, and the identification of novel bacterial targets for antibiotic treatment and for passive and active immunisation. The CAMs may represent such a target. For example, the RGD motif occurs in many microbial proteins and mediates binding to human integrins. RGD peptides and mimetics not only provide insights into microbial pathogenesis, but are potential therapeutics for various infec- 
tious diseases, in addition to thrombosis and cancer. ${ }^{85}$

The complete genome sequence is known for 10 bacterial pathogens and $\sim 30$ more are anticipated by the year 2000 (http:// www.tigr.org). Comparative genomics, increasingly important, has provided the knowledge that shared virulence determinants exist in several different bacterial genera, and that the pathogens among these have modified these determinants to perform particular functions and therefore facilitate their particular lifestyles. Currently, using nucleotide sequence data, we can compare entire microbial genomes and identify putative virulence factors with homologous function. In addition, the human genome mapping project will provide insights into the pathogenesis of microbial infection, particularly in the context of the interaction of prokaryotic and eukaryotic molecules. With improvements in animal modelling and probes for global microbial gene expression under different conditions such as microarrays, our understanding of the pathogenesis of infectious disease and its treatment and prevention will continue to improve. ${ }^{139}$

1 Freemont AJ. Adhesion molecules. F Mol Pathol: Clin Pathol 1998;51:175-84

2 Humphries MJ. The molecular basis and specificity of integrin-ligand interactions. $\mathcal{F}$ Cell Sci 1990;97:585-92.

3 Kerr JR. Type III (contact-dependent) secretion systems in Gram-negative bacteria. Reviews in Medical Microbiology. Gram-neg.

4 Puglsey AP. The complete general secretory pathway. Microbiol Rev 1993;57:50-108.

5 Anderson DM, Schneewind O. A mRNA signal for the type III secretion of Yop proteins by Yersinia enterocolitica. Science 1997;278:1140-3.

6 Henderson IR, Navarro-Garcia F, Nataro JP. The great escape: structure and function of the autotransporter proteins. Trends Microbiol 1998;6:370-8.

7 Cossart P, Boquet P, Normark S, et al. Cellular microbiology emerging. Science 1996;271:315-16.

8 Lally ET, Kieba IR, Sato A, et al. RTX toxins recognize a beta2 integrin on the surface of human target cells. F Biol Chem 1997;272:30463-9.

9 D'Enfert C. Rho, Rac and Cdc42. Trends Microbiol 1999;7:

10 Wright SD, Silverstein SC. Receptors for C3b and C3bi promote phagocytosis but not the release of toxic oxygen promote phagocytosis but not the release of toxic oxygen
from human phagocytes. $\mathcal{E}$ Exp Med 1983;158:2016-23.

11 Berton G, Laudanna C, Sorio C, et al. Generation of signals activating neutrophil functions by leukocyte integrinsLFA-1 and GP150/95, but not CR3, are able to stimulate the respiratory burst of human neutrophils. $\mathcal{F}$ Cell Biol 1992;116:1007-17.

12 Caron E, Hall A. Identification of two distinct mechanisms of phagocytosis controlled by different Rho GTPases. Science 1998;282:1717-21

13 Massol P, Montcourrier P, Guillemot JC, et al. Fc receptormediated phagocytosis requires CDC42 and Rac1. EMBO f 1998;17:6219-29.

14 Sherman IW, Crandall IE, Guthrie N, et al. The sticky secrets of sequestration. Parasitol Today 1995;11:378-84.

15 Barnwell JW, Asch AS, Nachmann RL, et al. A human $88 \mathrm{kDa}$ membrane glycoprotein (CD36) functions in vitro $88 \mathrm{kDa}$ membrane glycoprotein (CD 36$)$ functions in vitro
as a receptor for a cytoadherence ligand on Plasmodium as a receptor for a cytoadherence ligand on Plasmodium falciparum-72.

16 Ockenhouse CF, Tandon NN, Magowan C, et al. Identification of a platelet membrane glycoprotein as a falciparum malaria sequestration receptor. Science 1989;243:1469-71.

17 Berendt AR, Simmons DL, Tansley J, et al. Intercellular adhesion molecule 1 is an endothelial cell adhesion receptor for Plasmodium falciparum. Nature 1989;341:57-9.

18 Ockenhouse CF, Tegoshi T, Maeno Y, et al. Human vascular endothelial cell adhesion receptors for Plasmodium falciparum-infected erythrocytes: roles for endothelial leukocyte adhesion molecule 1 and vascular cell adhesion molecule 1. F Exp Med 1992;176:1183-9.

19 Mosser DM, Edelson PJ. The third component of complement, C3, is responsible for the intracellular survival of Leishmania major. Nature 1987;327:329-31.

20 Vines RR, Ramakrishnan G, Rogers JB, et al. Regulation of adherence and virulence by the Entamoeba histolytica lectin cytoplasmic domain, which contains a $\beta_{2}$ integrin motif. Mol Biol Cell 1998;9:2069-79.

21 Gale C, Finkel D, Tao N, et al. Cloning and expression of a gene encoding an integrin-like protein in Candida albicans. Proc Natl Acad Sci USA 1996;93:357-61.
22 Gale CA, Bendel CM, McClellan M, et al. Linkage of adhesion, filamentous growth, and virulence in Candida albicans to a single gene, INT1. Science 1998;279:1355-8.

23 DeMuri G, Hostetter M. Evidence for a beta 1 integrin fibronectin receptor in Candida tropicalis. Pediatr Res 1995;37:173.

24 Thornton BP, Vetvicka V, Pitman M, et al. Analysis of the sugar specificity and molecular location of the beta-glucanbinding lectin site of complement receptor type 3 (CD11b/ CD18). F Immunol 1996;156:1235-46.

25 Newman SL. Macrophages in host defense against Histoplasma capsulatum. Trends Microbiol 1998;7:67-71.

26 Newman SL, Bucher C, Rhodes J, et al. Phagocytosis of Histoplasma capsulatum yeasts and microconidia by human cultured macrophages and alveolar macrophages. Cellular cytoskeleton requirement for attachment and ingestion. $\mathcal{F}$ Clin Invest 1990;85:223-30.

27 Hostetter $M$. Adherence molecules in pathogenic fungi. Current Opinion in Infectious Diseases 1996;9:141-5.

28 Klotz S, Heni R, Smith R, et al. The fibronectin adhesin of Candida albicans. Infect Immun 1994;62:4679-81.

29 Santoni G, Gismondi A, Liu J, et al. Candida albicans expresses a fibronectin receptor antigenically related to $\alpha_{5} \beta_{1}$ integrin. Microbiology 1994;140:2971-9.

30 Bullock WE, Wright SD. Role of the adherence-promoting receptors, CR3, LFA-1, and p150,95, in binding of Histoplasma capsulatum by human macrophages. f Exp Med 1987;165:195-210.

31 Michie CA, Cohen J. The clinical significance of $\mathrm{T}$ cell superantigens. Trends Microbiol 1998;6:61-5.

32 Kansas G. Selectins and their ligands: current concepts and controversies. Blood 1996;88:3259-87.

33 Malik A, Lo S. Vascular endothelial adhesion molecules and tissue inflammation. Pharmacol Rev 1996;48:213-29.

34 Springer TA. Traffic signals for lymphocyte recirculation and leukocyte emigration: the multistep paradigm. Cell 1994;76:301-14.

35 Varki A. Selectin ligands: will the real ones please stand up. f Clin Invest 1997;99:158-62.

36 Stockbauer KE, Magoun L, Liu MY, et al. A natural variant of the cysteine protease virulence factor of group A streptococcus with an arginine-glycine-aspartic acid beta(3) and alpha(IIb)beta(3). Proc Natl Acad Sci USA 1999;96:242-7.

37 Marth T, Kelsall BL. Regulation of interleukin-12 by complement receptor 3 signalling. F Exp Med 1997;185:1987plem.

38 Ehlers MRW, Daffe M. Interactions between Mycobacterium tuberculosis and host cells: are mycobacterial sugars the key? Trends Microbiol 1998;6:328-35.

39 Verdegaal ME, Zegveld ST, van Furth R. Heat shock protein 65 induces CD62e, CD106, and CD54 on cultured human endothelial cells and increases their adhesiveness for Mengaud J, Ohayon H, Gounon P, et al. E-cadherin is the receptor for internalin, a surface protein required for entry
of L. monocytogenes into epithelial cells. Cell 1996;84:92332.

41 Dramsi S, Biswas I, Maguin E, et al. Entry of Listeria monocytogenes into hepatocytes requires expression of InlB, a surface protein of the internalin multigene family. $\mathrm{Mol}$ Microbiol 1995;16:251-61

42 Owen P, Meehan M, de Loughry-Doherty $\mathrm{H}$, et al. Phase-variable outer membrane proteins in Escherichia coli. FEMS Immunol Med Microbiol 1996;16:63-76.

43 Kaper JB. EPEC delivers the goods. Trends Microbiol 1998;6:169-72.

44 Kenny B, DeVinney R, Stein M, et al. Enteropathogenic E. coli (EPEC) transfers its receptor for intimate adherence into mammalian cells. Cell 1997;91:511-20.

45 Frankel G, Lider O, Hershkoviz R, et al. The cell-binding domain of intimin from enteropathogenic Escherichia coli domain of intimin from enteropathogenic Escherichia coli

46 Tran Van Nhieu G, Sansonetti PJ. Mechanism of shigella entry into epithelial cells. Curr Opin Microbiol 1999;2:51-5.

7 Watarai M, Funato S, Sasakawa C. Interaction of Ipa proteins of Shigella flexneri with alpha5-beta1 integrin promotes entry of the bacteria into mammalian cells. $\mathcal{F}$ Exp Med 1996;183:991-9.

48 Clark MA, Hirst BH, Jepson MA. M-cell surface beta1 integrin expression and invasin-mediated targeting of Yersinia pseudotuberculosis to mouse Peyer's patch $M$ cells. Infect Immun 1998;66:1237-43.

49 Isberg RR, Leong JM. Multiple $\beta_{1}$ chain integrins are receptors for invasin, a protein that promotes bacterial penetration into mammalian cells. Cell 1990;60:861-71.

50 Marra A, Isberg RR. Invasin-dependent and invasinindependent pathways for translocation of Yersinia pseudouberculosis across the Peyer's patch intestinal epithelium. Infect Immun 1997;65:3412-21.

51 Ohnishi Y, Beppu T, Horinouchi S. Two genes encoding serine protease homologues in Serratia marcescens and characterization of their products in Escherichia coli. $7 \mathrm{Bio}-$ chem 1997;121:902-13.

52 Coxon PY, Summersgill JT, Ramirez JA, et al. Signal transduction during Legionella pneumophila entry into human monocytes. Infect Immun 1998;66:2906-13.

53 Van Putten JP, Paul SM. Binding of syndecan-like cell surface proteoglycan receptors is required for Neisseria
gonorrhoeae entry into human mucosal cells. EMBO f 1995;14:2144-54 
54 Chen T, Belland RJ, Wilson J, et al. Adherence of pilusOpa+ gonococci to epithelial cells in vitro involves heparan .

55 Duensing TD, Van Putten JP. Vitronectin mediates internalization of Neisseria gonorrhoeae by Chinese hamster ovary cells. Infect Immun 1997;65:964-70

56 Gomez-Duarte OG, Dehio M, Guzman CA, et al. Binding of vitronectin to opa-expressing Neisseria gonorrhoeae mediates invasion of HeLa cells. Infect Immun 1997;65 3857-66.

57 Van Putten JP, Duensing TD, Cole RL. Entry of OpaA+ gonococci into HEp-2 cells requires concerted action of glycosaminoglycans, fibronectin and integrin receptors. Mol Microbiol 1998;29:369-80.

58 Dehio C, Gray-Owen SD, Meyer TF. The role of neisserial Opa proteins in interactions with host cells. Trends Microbiol 1998;6:489-95.

59 Geuijen CA, Willems RJ, Bongaerts M, et al. Role of the Bordetella pertussis minor fimbrial subunit, fimD, in colonisation of the mouse respiratory tract. Infect Immun 1997; 65:4222-8

60 Tuomanen E. In: Hokfelt B, ed. Cell adhesion molecules in the development of bacterial infections. The Netherlands: Excerpta Medica, 1992:297-308.

61 Van't Wout J, Burnette WN, Mar VL, et al. Role of carbohydrate recognition domains of pertussis toxin in adherence of Bordetella pertussis to human macrophages. Infect Immun 1992;60:3303-8.

62 Wong WSF, Luk JM. Signaling mechanisms of pertussis toxin-induced myelomonocytic cell adhesion: role of toxin-induced myelomonocytic cell adhesion: role of tyrosine phosphory

63 Lo SK, Lee S, Ramos RA, et al. Endothelial-leukocyte adhesion molecule 1 stimulates the adhesive activity of leukocyte integrin CR3 (CD11b/CD18, Mac-1, alpha m beta 2) on human neutrophils. F Exp Med 1991;173:1493-1500.

64 Everest P, Li J, Douce G, et al. Role of the Bordetella pertussis P.69/pertactin protein and the P.69/pertactin RGD motif in the adherence to and invasion of mammalian cells. Microbiology 1996;142:3261-8.

65 Fernandez RC, Weiss AA. Cloning and sequencing of a Bordetella pertussis serum resistance locus. Infect Immun 1994;62:4727-38

66 Finn TM, Stevens LA. Tracheal colonisation factor: a Bordetella pertussis secreted virulence determinant. $\mathrm{Mol}$ Microbiol 1995;16:625-34.

67 Li LJ, Dougan G, Novotny P, et al. P.70 pertactin, an outermembrane protein from Bordetella parapertussis: cloning, nucleotide sequence and surface expression in Escherichia coli. Mol Microbiol 1991;5:409-17

$68 \mathrm{Li} \mathrm{J}$, Fairweather NF, Novotny P, et al. Cloning, nucleotide sequence and heterologous expression of the protective
outer-membrane protein P.68 pertactin from Bordetella bronchiseptica. If Gen Microbiol 1992;138:1697-705.

69 Williams Bouyer NM, Hill EM. Involvement of host cell tyrosine phosphorylation in the invasion of Hep-2 cells by Bartonella bacilliformis. FEMS Microbiol Lett 1999;171: 191-201.

70 Wang JF, Kieba IR, Korostoff J, et al. Molecular and biochemical mechanisms of Pasteurella haemolytica
leukotoxin-induced cell death. Microb Pathog 1998;25:31731 .

71 Cinco M, Murgia R, Perticarari S, et al. Surface receptors of neutrophils towards B. burgdorferi. Wien Klin Wochensch 1998;110:866-9.

72 Coburn J, Leong JM, Urban JK. Integrin $\alpha_{11} \beta_{3}$ mediates binding of the Lyme disease agent Borrelia burgdorferi to
human platelets. Proc Natl Acad Sci USA 1993;90:705963.

73 Reife RA, Shapiro RA, Bamber BA, et al. Porphyromonas gingivalis lipopolysaccharide is poorly recognized by molecular components of innate host defense in a mouse model of early inflammation. Infect Immun 1995; 63:4686mod.

74 Meyer DH, Mintz KP, Fives-Taylor PM. Models of invasion of enteric and periodontal pathogens into epithelial cells: a comparative analysis. Crit Rev Oral Biol Med 1997;8:389 409.

75 Rottem S, Naot Y. Subversion and exploitation of host cells by mycoplasmas. Trends Microbiol 1998;6:436-40.

76 Hodtsev AS, Choi Y, Spanopoulou E, et al. Mycoplasma superantigen is a CDR3-dependent ligand for the T cell antigen receptor. $\mathcal{F} \operatorname{Exp}$ Med 1998;187:319-27.

77 Kobe B, Deisenhofer J. The leucine-rich repeat: a versatile binding motif. Trends Biochem Sci 1994;19:415-21.

78 Makhov AM, Hannah JK, Brennan MJ, et al. Filamentous haemagglutinin of Bordetella pertussis. A bacterial adhesin formed as a $50 \mathrm{~nm}$ monomeric rigid rod based on a 19 -residue repeat motif rich in beta strands and turns. $\mathcal{f}$ Mol Biol 1994;241:110-24.

79 Shevchenko DV, Akins DR, Robinson E, et al. Molecular characterisation and cellular localisation of TpLRR, a processed leucine-rich repeat protein of Treponema pallidum, the syphilis spirochete. F Bacteriol 1997;179: 3188-95.

80 Mengaud J, Lecuit M, Lebrun M, et al. Antibodies to the leucine rich repeat region of internalin block entry of Listeria monocytogenes into cells expressing $\mathrm{E}$ cadherin. Infect Immun 1996;64:5430-3.

81 Autenrieth LB, Firsching R. Penetration of $M$ cells and destruction of Peyer's patches by Yersinia enterocolitica: an
ultrastructural and histological study. $\mathcal{f}$ Med Microbiol ultrastructural and
82 Alrutz MA, Isberg RR. Involvement of focal adhesion kinase in invasin-mediated uptake. Proc Natl Acad Sci USA 1998; 95:13658-63.

83 Lundgren E, Carballeira N, Vazquez R, et al. Invasin of Yersinia pseudotuberculosis activates human peripheral B cells. Infect Immun 1996;64:829-35.

84 Sandros J, Tuomanen E. Attachment factors of Bordetella pertussis: mimicry of eukaryotic cell recognition molecules. Trends Microbiol 1993;1:192-6.

85 D'Souza SE, Ginsberg MH, Plow SF. Arginyl-glycylspartic acid (RGD) - a cell adhesion motif. Trends Biochem Sci 1991;16:246-50.

86 Leininger E, Roberts M, Kenimer JG, et al. Pertactin, an Arg-Gly-Asp-containing Bordetella pertussis surface protein that promotes adherence of

87 Minnick MF, Mitchell SJ, McAllister SJ. Cell entry and the pathogenesis of Bartonella infections. Trends Microbiol pathogenesis

88 Evans DJ, Almond JW. Cell receptors for picorna viruses as determinants of cell tropism and pathogenesis. Trends Microbiol 1998:6:198-202.

89 Mendelsohn CL, Wimmer E, Racaniello VR. Cellular receptor for poliovirus: molecular cloning, nucleotide sequence, and expression of a new member of the immunoglobulin superfamily. Cell 1989;56:855-65.

90 Gavrilovskaya IN, Shepley M, Shaw R, et al. Beta(3) integrins mediate the cellular entry of hantaviruses that cause respiratory failure. Proc Natl Acad Sci USA 1998;95: 7074-9.

91 Fox G, Parry NR, Barnett PV, et al. The cell attachment site on foot-and-mouth disease virus includes the amino acid sequence RGD (arginine-glycine-aspartic acid). F Gen Virol 1989;70:625-37.

92 Colonno RJ, Callahan PL, Long WJ. Isolation of a monoclonal antibody that blocks attachment of the major group of human rhinoviruses. F Virol 1986;57:7-12.

93 Greve JM, Davis G, Meyer AM, et al. The major human rhinovirus receptor is ICAM-1. Cell 1989;56:839-47.

94 Staunton DE, Merluzzi VJ, Rothlein R, et al. A cell adhesion molecule, ICAM-1, is the major surface receptor for rhinoviruses. Cell 1989;56:849-53.

95 Shafren DR, Bates RC, Agrez MV, et al. Coxsackieviruses $\mathrm{B} 1, \mathrm{~B} 3$, and $\mathrm{B} 5$ use decay accelerating factor as a receptor for cell attachment. F Virol 1995;69:3873-7.

96 Agrez MV, Shafren DR, Gu X, et al. Integrin alpha v beta 6 enhances coxsackievirus B1 lytic infection of human colon cancer cells. Virology 1997;239:71-7.

97 Bergelson JM, Cunningham JA, Droguett G, et al. Isolation of a common receptor for coxsackie B viruses and adenoviruses 2 and 5. Science 1997;275:1320-3.

98 Ward T, Pipkin PA, Clarkson NA, et al. Decay-accelerating factor CD55 is identified as the receptor for echovirus 7 sing CELICS, a rapid immuno-focal cloning method. EMBO $\mathcal{F}$ 1994;13:5070-4

99 Bergelson JM, Chan M, Solomon KR, et al. Decayaccelerating factor (CD55), a glycosylphosphatidylinositolanchored complement regulatory protein, is a receptor for several echoviruses. Proc Natl Acad Sci USA 1994;91:6245-

100 Powell RM, Schmitt V, Ward T, et al. Characterization of echoviruses that bind decay accelerating factor (CD55): evidence that some haemagglutinating strains use more than one cellular receptor. F Gen Virol 1998;79:1707-13.

101 Roivainen M, Piirainen L, Hovi T, et al. Entry of coxsackievirus A9 into host cells: specific interactions with alpha v beta 3 integrin, the vitronectin receptor. Virology 1994;203: $357-65$.

102 Hyypia T, Horsnell C, Maaronen M, et al. A distinct picornavirus group identified by sequence analysis. Proc Natl Acad Sci USA 1992;89:8847-51.

103 Kaplan G, Totsuka A, Thompson P, et al. Identification of a surface glycoprotein on African green monkey kidney cells as a receptor for hepatitis A virus. $E M B O \mathcal{F}$ 1996;15: 4282-96.

104 Huber SA. VCAM-1 is a receptor for encephalomyocarditis virus on murine vascular endothelial cells. $\mathcal{F}$ Virol 1994; 68:3453-8.

105 Poli G, Pantaleo G, Fauci AS. Immunopathogenesis of 位 Infect Dis 1993; 17(suppl 1):S224-9.

106 Moore DAJ, Henderson D, Gazzard BG. Neutrophil adhesion molecules in HIV disease. Clin Exp Immunol 1998;114:73-7.

107 Levy JA. Three new human herpesviruses (HHV6, 7 and 8). Lancet 1997;349:558-63.

108 Lusso P, Secchiero P, Crowley RW, et al. CD4 is a critical component of the receptor for human herpesvirus 7: interference with human immunodeficiency virus. Proc Natl Acad Sci USA 1994;91:3872-6.

09 Warren AP, Owens CN, Borysiewicz LK, et al. Downregulation of integrin alpha 1/beta 1 expression and assocition with cell rounding in human cytomegalovirusinfected fibroblasts. F Gen Virol 1994;75:3319-25.

110 Summerford C, Bartlett JS, Samulski RJ. Alpha V beta 5 integrin: a co-receptor for adeno-associated virus type 2 infection. Nat Med 1999;5:78-82.

111 Stone DM, Norton LK, Davis WC. Modulation of bovine leukaemia virus-associated spontaneous lymphocyte proliferation by monoclonal antibodies to lymphocyte surface molecules. Clin Immunol Immunopathol 1997;83:156-64.

112 Sinclair JP, Shearer WT. Current status of CD4-based therapies for prophylaxis and treatment of HIV infection. Biodrugs 1997;8:128-38. 
113 Hengel H, Brune W, Koszinowski UH. Immune evasion by cytomegalovirus - survival strategies of a highly adapted

114 Dobrescu D, Ursea B, Pope M, et al. Enhanced HIV-1 replication in $\mathrm{V}$ beta $12 \mathrm{~T}$ cells due to human cytomegalovirus in monocytes: evidence for a putative herpesvirus superantigen. Cell 1995;82:753-63.

115 Brown EJ, Lindberg FP. Leucocyte adhesion molecules in host defence against infection. Ann Med 1996;28:201-8.

116 Hynes RO. Integrins: a family of cell surface receptors. Cell 1987;48:547-54.

117 Tedder TF, Steeber DA, Chen A, et al. The selectins: vascular adhesion molecules. FASEB f 1995;9:866-73.

118 Bevllacqua MP, Stenglelln S, Ginbrone MA, Jr, et al. Endothelial leucocyte adhesion molecule 1: an inducible receptor for neutrophils related to complement regulatory proteins and lectins. Science 1989;243:1160-5.

119 Geng JG, Bevllacqua MP, Moore KL, et al. Rapid neutrophil adhesion to activated endothelium mediated by GMP140. Nature 1990;343:757-60.

120 Koedam JA, Cramer EMJ, Brlend E, et al. P-selectin, a granule membrane protein of platelets and endothelial granule membrane protein of platelets and endothelial
cells, follows the regulated secretory pathway in AtT-20 cells, follows the regulated secret
cells. F Cell Biol 1992;116:617-25.

121 Berlin C, Berg EL, Briskin MJ, et al. Alpha 4 beta 7 integrin mediates lymphocyte binding to the mucosal vascular addressin MAdCAM-1. Cell 1993;74:185.

122 Briskin MJ, McEvoy LM, Buthcer EC. MAdCAM-1 has homology to immunoglobulin and mucin-like adhesion receptors and to IgA1. Nature 1993;363:461-4.

123 Mawby WJ, Holmes CH, Anstee DJ, et al. Isolation and characterisation of CD47 glycoprotein: a multispanning membrane protein which is the same as integrin-associated protein (IAP) and the ovarian tumour marker $\mathrm{OA} 3$. Biochem ₹ 1994;304:525-30.

124 Reinhold MR, Lindberg FP, Plas D, et al. In vivo expression of alternatively spliced forms of integrinassociated protein (CD47). F Cell Sci 1995;108:3419-25.

125 Muller WA, Weigl SA, Deng X, et al. PECAM-1 is required for transendothelial migration of leucocytes. $\mathcal{F}$ Exp Med 1993;178:449-60.

126 Cooper D, Lindberg FP, Gamble JR, et al. The transendothelial migration of neutrophils involves integrin associated protein (CD47). Proc Natl Acad Sci USA 1995; 92:3978-82.

127 Butcher EC. Leucocyte-endothelial cell recognition: three (or more) steps to specificity and diversity. Cell 1991;67 1033-6.
128 Von Andrian UH, Berger EM, Ramezani L, et al. In vivo behavior of neutrophils from two patients with distinct inherited leucocyte adhesion deficiency syndromes. $\mathcal{F}$ Clin Invest 1993;91:2893-7.

129 Etzioni A, Harlan JM, Pollack S, et al. Leucocyte adhesion deficiency (LAD) II: a new adhesion defect due to absence of sialyl Lewis X, the ligand for selectins. Immunodeficiency 1993;4:307-8.

130 Frydman M, Etzioni A, Ekdlitz-Markus T, et al. RambamHasharon syndrome of psychomotor retardation, short stature, defective neutrophil motility, and Bombay phenotype. Am f Med Genet 1992;44:297-302.

131 Harlan JM. Leucocyte adhesion deficiency syndrome: insights into the molecular basis of leucocyte emigration. Clin Immunol Immunopathol 1993;67:S1 6-24.

132 Kishimoto TK, Hollander N, Roberts RM, et al. Heterogeneous mutations in the $\beta$ subunit common to the LFA-1, Mac-1, and p150,95 glycoproteins cause leucocyte adhesion deficiency. Cell 1987;50:192-202.

133 Lindberg FP, Gresham HD, Schwarz E, et al. Molecular cloning of integrin-associated protein: an immunoglobulin family member with multiple membrane spanning domains implicated in alpha-v, beta-3-dependent ligand binding. $\mathcal{F}$ Cell Biol 1993;123:485-96.

134 Piall L, Hammel P, Uherek C, et al. CD31/PECAM-1 is a ligand for alpha-v, beta-3 integrin involved in adhesion of leucocytes to endothelium. F Cell Biol 1995;130:45160.

135 Lampugnani MG, Reesnati M, Dejani E, et al. The role of integrins in the maintenance of endothelial monolayer integrity. F Cell Biol 1991;112:479-80.

136 Gresham HD, Goodwin JL, Anderson DC, et al. A novel member of the integrin receptor family mediates Arg-GlyAsp stimulated neutrophil phagocytosis. F Cell Biol 1989;108: 1935-43.

137 Gresham HD, Adams SP, Brown EJ. Ligand binding specificity of the leucocyte response integrin expressed by human neutrophils. F Biol Chem 1992;267:13895-902.

138 Zhou MJ, Brown EJ. Leucocyte response integrin and integrin associated protein act as a signal transduction unit in generation of a phagocyte respiratory burst. $\mathcal{F}$ Exp Med 1993;178:1165-74.

139 Miller JF, Cossart P. Bacterial pathogenesis: before the post-genomic era. Curr Opin Microbiol 1999;2:15-17. 